\title{
THE POSSIBLE EFFECTS OF SILYMARIN ON CEREBRUM WITH EXPERIMENTAL HEPATIC ENCEPHALOPATHY IN RATS
}

\author{
Ozgun Teksoy ${ }^{1}$, Varol Sahinturk ${ }^{2}$, Mustafa Cengiz ${ }^{*}{ }^{\square}$, Behcet İnal ${ }^{4}$, Adnan \\ Ayhanci 1 \\ ${ }^{1}$ Faculty of Arts and Science, Department of Biology, Eskişehir Osmangazi University, Eskișehir, \\ Turkey \\ ${ }^{2}$ Faculty of Medicine, Department of Histology and Embryology, Eskişehir Osmangazi University, \\ Eskişehir, Turkey \\ ${ }^{3}$ Faculty of Education, Department of Elementary Education, Siirt University, Siirt, Turkey \\ ${ }^{4}$ Faculty of Agriculture, Department of Agricultural Biotechnology, Siirt University, Siirt, Turkey
}

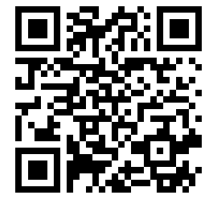

\section{DOI: https://doi.org/10.29121/granthaalayah.v8.i8.2020.946}

Article Type: Research Article

Article Citation: Ozgun Teksoy, Varol Sahinturk, Mustafa Cengiz, Behcet İnal, and Adnan Ayhanci. (2020). THE POSSIBLE EFFECTS OF SILYMARIN ON CEREBRUM WITH EXPERIMENTAL HEPATIC ENCEPHALOPATHY IN RATS. International Journal of Research GRANTHAALAYAH, 8(8), 140-146. https://doi.org/10.29121/granthaa layah.v8.i8.2020.946

Received Date: 02 August 2020

Accepted Date: 26 August 2020

Keywords:

Hepatic Encephalopathy

Rat

DLPFC

Silymarin

Immunohistochemistry

\section{ABSTRACT}

Background: The relationship between liver diseases and neurological defects is well established. Hepatic encephalopathy (HE) has been seen both in people with acute liver failure (ALF) and chronic liver disease (CLF). HE is a complex neuropsychiatric syndrome that is seen in patients suffering from liver dysfunction. Silymarin ( $\mathrm{Sm}$ ) has antioxidant, anti-inflammatory, and anti-carcinogenic features. In this study, the possible protective effects of silymarin were investigated against dorsolateral prefrontal cortex (DLPFC) damage induced by thioacetamide (TAA).

Method: To achieve this, male Sprague Dawley rats (200-250 g) were randomly divided into four groups, with 7 animals comprising each group: the control group, $50 \mathrm{mg} / \mathrm{kg}$ TAA group, $50 \mathrm{mg} / \mathrm{kg} \mathrm{Sm}+$ TAA group, and $100 \mathrm{mg} / \mathrm{kg} \mathrm{Sm}+$ TAA group.

Results: Differences between the groups were determined by performing immunohistochemical analysis of the PFC. Bax, TNF- $\alpha$, and TUNEL expression increased in the brain tissue of the experimental group where only TAA was administered.

Conclusions: It was observed that in high doses in particular $(100$ $\mathrm{mg} / \mathrm{kg} \mathrm{Sm}+$ TAA group), Sm was effective in preventing PFC damage caused by TAA. It was determined that $100 \mathrm{mg} / \mathrm{kg} \mathrm{Sm}$ significantly reduces TAA-induced inflammation (TNF- $\alpha$ and H\&E) and apoptosis (Bax, TUNEL) in brain tissue.

\section{INTRODUCTION}

Abnormal behavior and cognition impairment have been observed in the brains of patients suffering from acute and chronic liver failure, which is, in turn, followed by the detection of edema in the brain cells caused by increasing ammonia levels in the blood. This syndrome is called hepatic encephalopathy (HE) and is the result of several factors, defined as intrinsic (genetic) or extrinsic (viral, alcohol) [1]. According to the International Association of Hepatic Encephalopathy and Nitrogen Metabolism (ISHEN), thioacetamide (TAA), D-galactosamine, and carbon tetrachloride

(C) 2020 The Author(s). This is an open access article distributed under the terms of the Creative Commons Attribution License, which permits unrestricted use, distribution, and reproduction in any medium, provided the original author and source are credited. 
have been commonly used to create an experimental animal model of HE [2]. TAA, used in the present study, metabolized in the liver [3]. The metabolizing process occurs in two stages: firstly, the TAA-S-oxide (TASO) appears followed by S, S-dioxide (reactive form, TASO2). This metabolizing process is executed through hepatic cytochrome P450 enzymes and the FAD-containing monooxygenase (FMO) [4].

Thecerebrum (telencephalon), responsible for controlling our emotions, hearing, vision, personality, and much more, is the largest part of the brain [5]. It is one of the areas most affected by HE precisely because it is such a big section of the brain [6], [7], [8], [9]. Our study is focused on the dorsolateral prefrontal cortex (DLPFC), the front most of the frontal lobe [10]. It is responsible for complex behavior such as planning, decision making, expression, etc [11], [12].

Several drugs are commonly used in HE treatment but, unfortunately, a host of side effects has also been reported alongside their use. For this reason, researchers are turning to herbal ingredients in their quest for a suitable treatment for HE. Silymarin ( $\mathrm{Sm}$ ), obtained from the seeds and fruits of Silybum marianum, is one of them. $\mathrm{Sm}$ is a mixture of isomeric flavonoids (silybin, is silybin, and silychristin) [9]. It can be used in high doses without any resulting side effects in either humans or animals [13]. It has a hepatoprotective feature, while at the same time demonstrating free radical scavenging and cell membrane balancing activity [13], [14], [15], [16], [17]. Several studies have shown that Sm also has a neuroprotective effect [18]. This effect is largely related to the inhibition of oxidative stress molecules in the brain [19] but is also a result of the induction of pathways involved in neuroprotection, such as the inflammatory pathways [20], [21]. Moreover, a previous study demonstrated which Sm attenuates 6-OHDA-induced motor in-coordination in rats [22].

This study aims to show brain damage caused by TAA-induced liver damage as well as to throw some light on the protective effect of Sm on the brain in animal models with HE. To better understand this effect, the DLPFCs of rats were examined immunohistochemically via apoptotic markers.

\section{MATERIAL-METHOD}

\subsection{CHEMICALS}

TAA (Cat No: 62-55-5), DMSO (Cat No: 67-68-5), and Sm (Cat No:65666-07-1)were purchased from Sigma Chemical Co. (St. Louis, MO, USA) and immunohistochemistry (IHC) antibodies were obtained from Santa Cruz Biotech (Santa Cruz, USA).

\subsection{ANIMALS}

8 weeks-old male Sprague-Dawley rats $(200-250 \mathrm{~g})$ were housed at $25^{\circ} \mathrm{C}$ and exposed to a12 h light-dark cycle. Food and tap water were provided ad libitum. Animal experiments were performed according to the National Institutes of Health (NIH) Guide for the Care and Use of Laboratory Animals (Reg. No. KU/IAEC/PhD/100 dated 26.07.2012). This study was carried out with the permission of the Eskişehir Osmangazi University Local Animal Ethics Committee (No: 513-2 / 2016).

\subsection{THE EXPERIMENTAL DESIGN}

The groups were determined in accordance with previous studies [23].

Untreated group: $0.5 \mathrm{~mL}$ of water with $0.2 \%$ DMSO was administered orally to each animal for the first 14 days, followed by an intraperitoneal injection of $0.5 \mathrm{~mL}$ serum physiologic for the remaining 14 days.

TAA group: $50 \mathrm{mg} / \mathrm{kg}$ TAA ( $1 \mathrm{~mL} / \mathrm{kg}$ b.w.) was intraperitoneally injected to each animal for the second period of 14 days.

Low dose treatment group: $50 \mathrm{mg} / \mathrm{kg} \mathrm{Sm} \mathrm{(1} \mathrm{mL/kg} \mathrm{b.w.)} \mathrm{was} \mathrm{administered} \mathrm{orally} \mathrm{to} \mathrm{each} \mathrm{animal} \mathrm{for} \mathrm{the} \mathrm{first} 14$ days, followed by $50 \mathrm{mg} / \mathrm{kg}$ TAA ( $1 \mathrm{~mL} / \mathrm{kg}$ b.w.) intraperitoneally injected into each animal for the remaining second 14 days.

High dose treatment group: $100 \mathrm{mg} / \mathrm{kg} \mathrm{Sm} \mathrm{(1} \mathrm{mL/kg} \mathrm{b.w.)} \mathrm{was} \mathrm{administered} \mathrm{orally} \mathrm{to} \mathrm{each} \mathrm{animal} \mathrm{for} \mathrm{the} \mathrm{first}$ 14 days, followed by $50 \mathrm{mg} / \mathrm{kg}$ TAA $(1 \mathrm{~mL} / \mathrm{kg}$ b.w.) intraperitoneally injected to each animal for the remaining second 14 days. 
The Possible Effects of Silymarin on Cerebrum with Experimental Hepatic Encephalopathy in Rats

$5 \%$ dextrose containing $0.9 \% \mathrm{NaCl}$ and potassium $(20 \mathrm{mEq} / \mathrm{L})$ was injected into all animals daily to prevent weight loss, hypoglycemia, and renal failure [24].

1 day after the last TAA injection, a laparotomy was drastically performed under sterile conditions and all rats were anesthetized with ketamine/xylazine (5/1 ratio); blood samples were then collected from the left ventricle of the heart and centrifuged at 3000 rpm for 10 mins after which serum was obtained.

\subsection{IMMUNOSTAINING}

Immunostaining was performed based on the standard procedure with some modifications. Zivic Rat Brain Slicers were used to cut the brain into slices. After fixing the cerebrum tissues (DLPFC) $\left(56^{\circ} \mathrm{C}, 1 \mathrm{night}\right)$, they were deparaffinized with xylene and then rehydrated in ethanol of various percentages. They were then immersed in fresh and ice-cold methanol containing $1 \% \mathrm{H}_{2} \mathrm{O}_{2}$ forabout 20 mins to eliminate the effect of endogenous peroxidase. Samples rinsed with PBS were incubated in blocking buffer (PBS containing 3\% BSA, 0,1\% Tween-20) at 25ㄷ [25].

Samples were incubated with anti-Bax (Abcam, cat: ab53154) and anti-TNF- $\alpha$ (Abcam, cat: ab6671) antibodies (Millipore, cat: S7101) in a blocking solution for $1 / 2$ day at $4^{\circ} \mathrm{C}$ and washed with PBS $\left(25^{\circ} \mathrm{C}\right)$. This was then followed by incubation with a horseradish peroxidase (HRP) antibody (Abcam) (1:2500) in blocking solution for 120 minutes at $25^{\circ} \mathrm{C}$. After washing with PBS, the samples were incubated with $0,23,3^{\prime} \%$-diaminobenzidine (DAB), and then later rinsed with distilled water. All samples were counterstained with hematoxylin. Immunoreactivity between groups was examined under a fluorescent microscope with a camera (Olympus-DP70 camera).

Apoptotic cells were detected according to the apoptotic detection kit guide, (Millipore, Cat No: S7101). After the sections had been sliced at $5 \mu \mathrm{m}$ thicknesses, they were treated with $20 \mu \mathrm{g} / \mathrm{ml}$ proteinase $\mathrm{K}$ in $0.1 \mathrm{~mol} / \mathrm{l}$ Tris$\mathrm{HCl}$ buffer ( $\mathrm{pH} 7.4$ ) for 15 minutes. They were then incubated with $100 \mu \mathrm{L}$ equilibration buffer at $25^{\circ} \mathrm{C}$ for $15 \mathrm{~min}$ and later with rTdT incubation buffer ( $45 \mu \mathrm{L}$ equilibration buffer, $5 \mu \mathrm{L}$ nucleotide mix, $1 \mu \mathrm{L}$ rTdT enzyme) at $37^{\circ} \mathrm{C}$ 60 minutes in a humidified chamber. The reaction was completed by treating the samples with $2 \times$ SSC for 15 minutes at $25^{\circ} \mathrm{C}$. The samples were stained with $1 \mu \mathrm{g} / \mathrm{ml}$ propidium iodide for analyzing in a fluorescence microscope $(620 \mathrm{~nm}) .500$ healthy cells were examined in a fluorescence microscope and those that had a red appearance were considered TUNEL positive [26].

\section{RESULTS AND DISCUSSIONS}

This study has described how brain damage due to TAA-induced liver depredation was treated by $100 \mathrm{mg} / \mathrm{kg}$ Sm. It was observed that apoptosis (Bax, TUNEL) and inflammation (TNF- $\alpha$ ) reduced in the TAA group depending on the administration of Sm treatment. However, Bax, TUNEL, and TNF- $\alpha$ expression levels did not reduce in the 50 $\mathrm{mg} / \mathrm{kg} \mathrm{Sm+TAA} \mathrm{group} \mathrm{(Figures} \mathrm{1-3).}$

The Bcl-2 family (Bcl-2, Bax, Bim, Bid, Bak, and Bcl-xL) plays an important role in initiating an intrinsic apoptotic pathway [26], [27], [28], [29], [30]. Bax, a pro-apoptotic member of the family, promotes cell death via permeabilization of the mitochondrial outer membrane. In contrast, Bcl-2 (an anti-apoptotic member) prevents apoptosis by blocking Bax activity [28], [29]. The balance between Bax and Bcl-2 can determine cellular fate. Mutagenic chemicals such as TAA trigger apoptosis, with some studies, successfully demonstrating increased expression of Bax and decreased Bcl-2 expression following TAA-induced hepatotoxicity [24]. Brain damage caused by TAA has also been demonstrated [30], [31], [32], [33], [34], [35]. Another study led by El-Ghazaly established that when TAA-induced Wistar HE rats are administrated local or whole-body low dose $\gamma$ radiation (0.5 Gy), increased caspase-3 expression level occurs in the brain immunochemically [32]. Khanna and Trigun (2016) found that $100 \mathrm{mg} / \mathrm{kg}$ TAA in Wistar rats significantly increased the level of cerebrum Bax expression [33].

Tumour necrosis factor-alpha (TNF- $\alpha$ ), a cytokine, plays a role in inflammation and is responsible for the process which results in cell death. As a result of excessive oxidative stress, neuronal apoptosis begins depending on mitochondrial dysfunction or TNF family receptors activation [34]. El-Marasy et al. (2018) showed that the TNF- $\alpha$ content in brain tissue was enhanced 1.46-fold compared to normal rats in TAA $(100 \mathrm{mg} / \mathrm{kg})$ induced-Wistar HE rats. They also noted that plasma TNF- $\alpha$ levels were significantly increased in Wistar rats given $150 \mathrm{mg} / \mathrm{kg}$ TAA when compared to the control group [36].

Terminal deoxynucleotidyl transferase dUTP nick end labeling (TUNEL) is a method used for apoptosis detection and it detects DNA fragmentation by labeling the $3^{\prime}$ - hydroxyl terminal in dsDNA [37]. Bustamante and 
colleagues found that the apoptosis rate in a rat MHE (minimal hepatic encephalopathy) model performed by surgery increased by 2.3 times compared to the control group [37].

Several studies have been conducted on the neuroprotective effect of Sm. Haddadi et al. treated neurotoxicity induced by 6-hydroxydopamine (6-OHDA) in Wistar rats with Sm daily, 100, 200, and $300 \mathrm{mg} / \mathrm{kg}$ injected into SNc (substantia nigra pars compacta) [26]. As a consequence, the Bcl-2 level increased while the Bax and TUNEL levels decreased. However, the caspase-3 level did not change significantly in any group. Our experimental results show that Silymarin may have neuroprotective effects on neurotoxicity caused by hepatic encephalopathy.
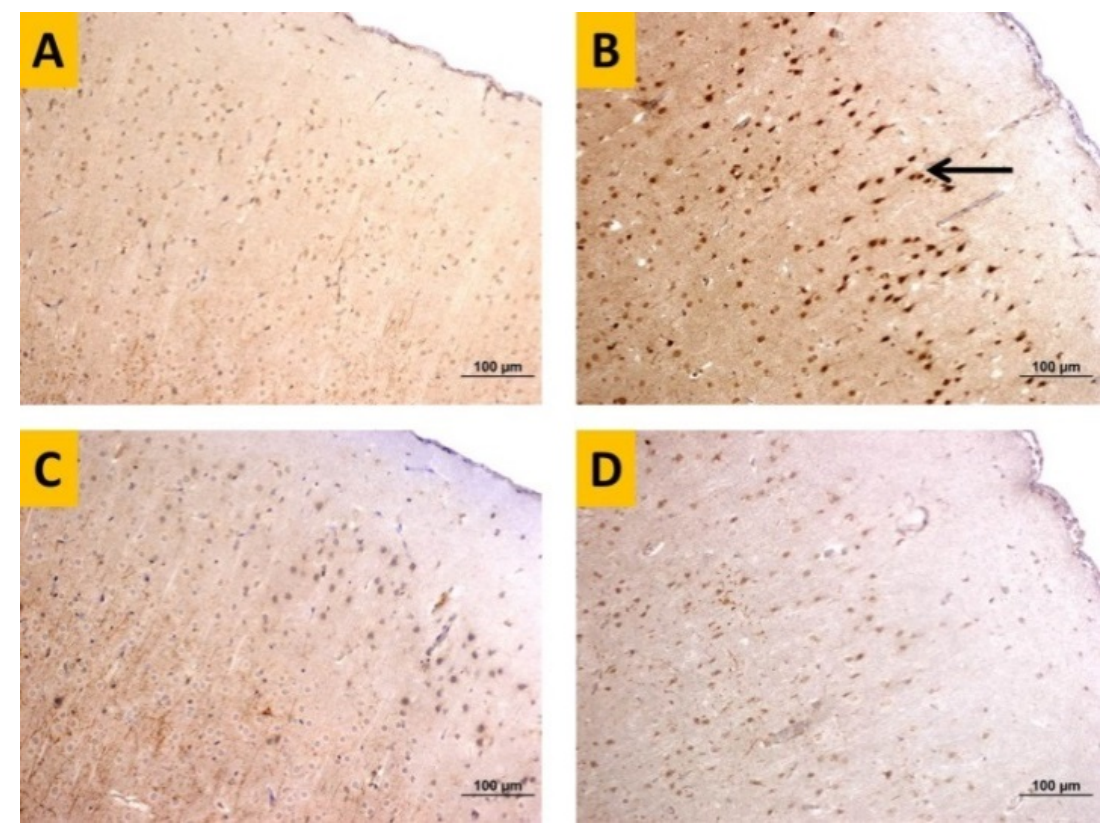

Figure 1: Bax immunoreactivity in neurons in brain cortex sections of rats belonging to experimental groups. Bax immunoreactivity is indicated by a neuron that reacts positively (arrow). A: Weak reaction in neurons in the control group.B: Strong positive reaction in the TAA group.C: Weak reaction in the TAA + low dose Sm group and D: Weak reaction in the TAA + high dose Sm group. All bars are $100 \mu \mathrm{m}$.
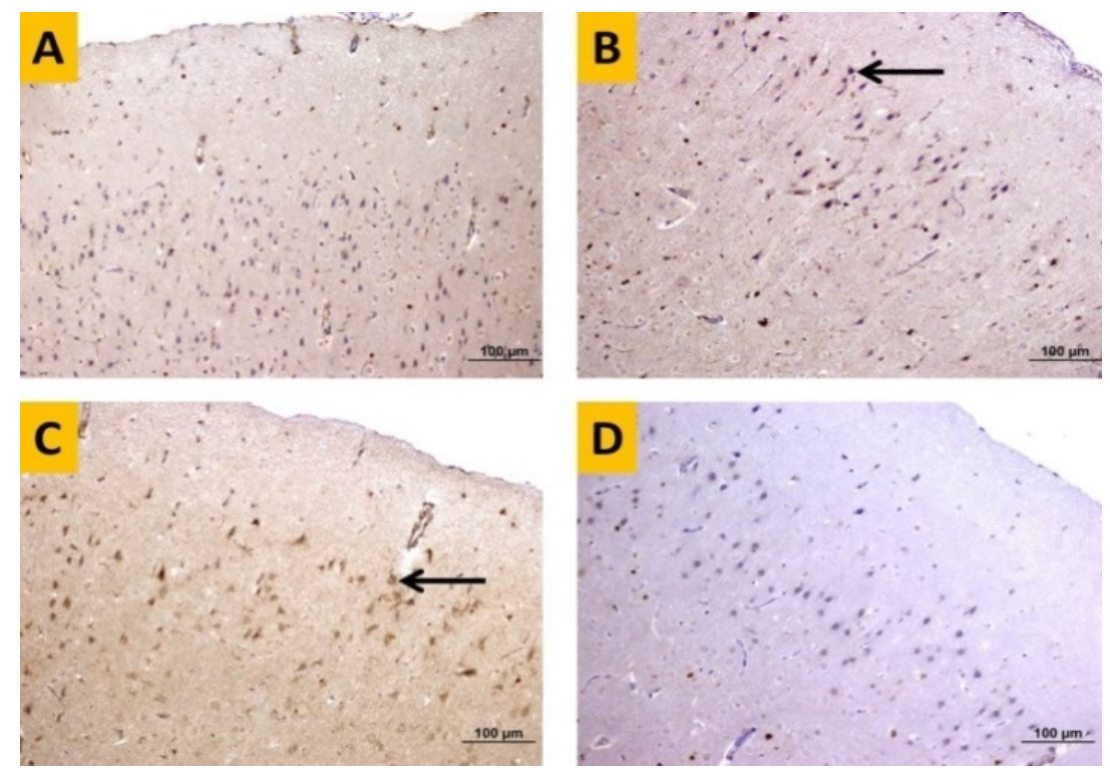

Figure 2: TUNEL immunoreactivity in neurons in the brain cortex sections of rats belonging to experimental groups. Some of the neurons that reacted positively are indicated by (arrows). A: Weak reaction in neurons in the control group.B: Strong positive reaction in the TAA treated group. C: Moderate reaction in the TAA + low dose Sm group and D: Weak reaction in the TAA + high dose Sm group. All bars are $100 \mu \mathrm{m}$. 

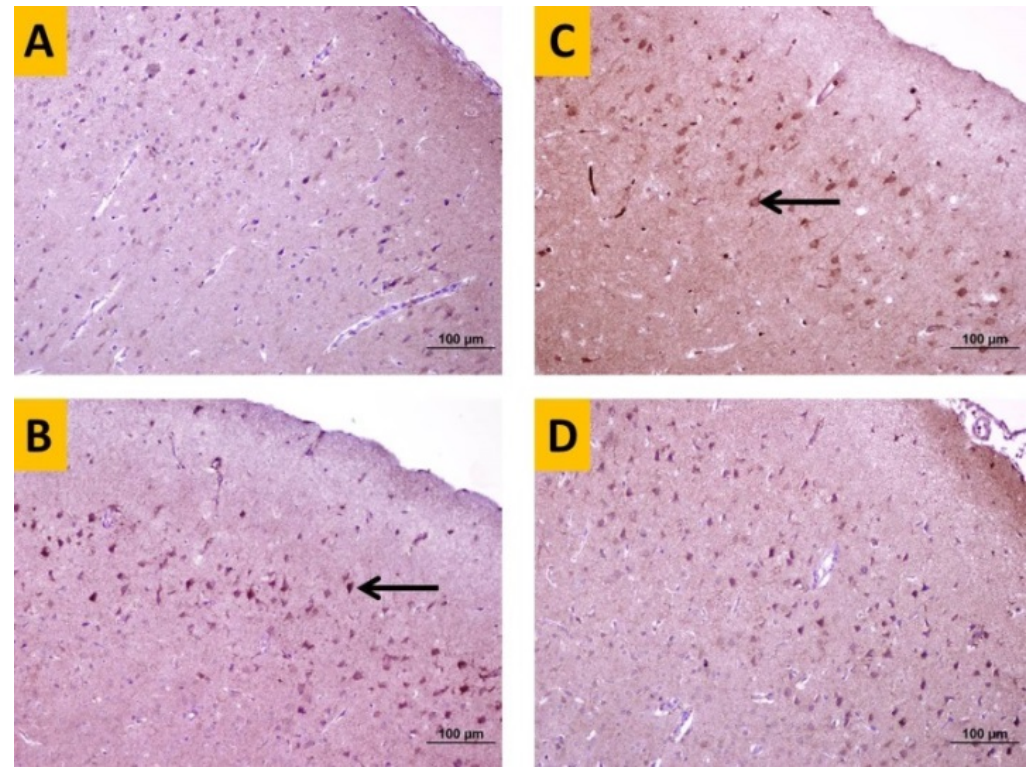

Figure 3: TNF- $\alpha$ immunoreactivity in neurons in brain cortex sections of rats belonging to experimental groups. Some of the neurons that reacted positively are indicated by (arrows). A: Weak reaction in neurons in the control group. B: Strong positive reaction in the TAA treated group. C: Moderate reaction in the TAA + low dose Sm group and D: Weak reaction in the TAA + high dose Sm group. All bars are $100 \mu \mathrm{m}$.

\section{CONCLUSION}

Silymarin is an extremely good hepatoprotective agent. For this reason, it has the potential to be used as a protective agent in hepatic encephalopathy, which causes both liver and brain damage. Our experimental findings support this hypothesis. However, since the bioavailability of Sm is rather low, we propose two different strategies to increase its effectiveness. First, the active ingredients of Sm should be investigated more comprehensively, considering synergistic and antagonistic effects. Secondly, new materials containing Sm should be prepared to increase the bioavailability of $\mathrm{Sm}$, such as sugar-coated tablets, its own micro emulsifying drug delivery system (SMEDDS), or beta-cyclodextrin inclusion.

\section{SOURCES OF FUNDING}

This research received no specific grant from any funding agency in the public, commercial, or not-for-profit sectors.

\section{CONFLICT OF INTEREST}

The author have declared that no competing interests exist.

\section{ACKNOWLEDGMENT}

This study (coded 2017-1621) from Özgün Teksoy's doctoral dissertation was supported by Eskişehir Osmangazi University.

\section{REFERENCES}

[1] Felipo V: Hepatic encephalopathy: effects of liver failure on brain function in Nat Rev Neurosci. (2013) 14(12):851-8.

[2] Butterworth RF, Norenberg MD, Felipo V, Ferenci P, Albrecht J, and Blei AT Experimental models of hepatic encephalopathy: ISHEN guidelines. Liver Int. (2009) 29(6):783-8. 
[3] Dyroff MC and Neal RA: Studies of the mechanism of metabolism of thioacetamide S-oxide by rat liver microsomes in Mol Pharmacol. (1983) 233:219-227.

[4] Hunter AL, Holscher MA, and Neal RA. Thioacetamide-induced hepatic necrosis. I. Involvement of the mixedfunction oxidase enzyme system in J Pharmacol Exp Therap. (1977) 200:439-448.

[5] Sarma D, Hajovsky H, Koen YM, Galeva NA, Williams TD, Staudinger JL, and Hanzlik RP: Covalent modification of lipids and proteins in rat hepatocytes, and in vitro, by thioacetamide metabolites in Chem Res Toxicol. (2012) 17;25(9):1868-77.

[6] Arnould-Taylor W: A Textbook of Anatomy and Physiology. Nelson Thornes, (2015).

[7] Rao KV and Norenberg MD: Cerebral energy metabolism in hepatic encephalopathy and hyperammonemia in Metab Brain Dis. (2001) 16(1-2):67-78.

[8] Lockwood AH, Yap EW and Wong WH: Cerebral ammonia metabolism in patients with severe liver disease and minimal hepatic encephalopathy inJ Cereb Blood Flow Metab:(1991) 11(2):337-41.

[9] Kumar G, Taneja A and Kandiah PA: Brain and the Liver: Cerebral Edema, Hepatic Encephalopathy and Beyond in hepatic Critical Care. (2020) 83-103.

[10] Liu G, Wang T, Wang T, Song J, and Zhou Z. Effects of apoptosis-related proteins caspase 3, Bax and Bcl 2 on cerebral ischemia rats in Biomed. Rep. (2013) 1:861-867.

[11] Elisabeth M, Steven W, and Kim Grahatle: The Evolution of Memory Systems: Ancestors, Anatomy, and Adaptations. Oxford University Press. Oxford. (2016) pp: 22-24.

[12] Cengiz, M., Kutlu, HM, Burukoglu, DD, \& Ayhancl, A. (2015). A comparative study on therapeutic effects of silymarin and silymarin-loaded solid lipid nanoparticles on D -GaIN / TNF- $\alpha$-induced liver damage in Balb / c mice. Food and Chemical Toxicology, 77, 93-100.

[13] Gabrieli JD, Poldrack RA, and Desmond JE: The role of left prefrontal cortex in language and memory in PNAS. (1998)95(3):906-13.

[14] Saller R, Meier R, and Brignoli R: The use of Silymarin in the treatment of liver diseases in Drugs. (2001); 61:2035-2063.

[15] Teksoy O, Sahinturk V, Cengiz M, İnal B, Ayhancı A: The Protective Effects of Silymarin on ThioacetamideInduced Liver Damage: Measurement of miR-122, miR-192, and miR-194 Levels. Applied Biochemistry and Biotechnology, 06 Dec 2019, 191(2): 528-539.

[16] Cengiz, M: Renoprotective effects of Silybum marianum (L.) Gaertn (Silymarin) on thioacetamide-induced renal injury: Biochemical and histopathological approach. Pakistan Journal of Pharmaceutical Sciences. Sep2018 Supplement Special, p2137-2141.

[17] Muriel P, and Mourelle M: Prevention by silymarin of membrane alterations in acute CCL4 liver damage in J Appl Toxicol. (1990a)10;275-279.

[18] Muriel P and Mourelle M. The role of membrane composition in ATPase activities of cirrhotic rat liver: effect of silymarin in J Appl Toxicol. (1990b) 10;281-284.

[19] Abdel-Moneim AM, Al-Kahtani MA, El-Kersh MA, and Al-Omair MA. Free radical-scavenging, antiinflammatory/anti-fibrotic, and hepatoprotective actions of taurine and silymarin against CCl4 induced rat liver damage in PLoS ONE. (2015)10: e0144509.

[20] Galhardi F, Mesquita K, Monserrat JM, and Barros DM: Effect of Silymarin on biochemical parameters of oxidative stress in aged and young rat brain in Food ChemToxicol. (2009); 47:2655-2660.

[21] Wang MJ, Lin WW, Chen HL, Chang YS, Ou HC, Kuo JS, Hong JSand Jeng KCG: Silymarin protects dopaminergic neurons against lipopolysaccharide-induced neurotoxicity by inhibiting microglia activation in Eur J Neurosci. (2002) 16:2103-2112.

[22] Wang C, Wang Z, Zhang X, Zhang X, Dong L, Xing Y, Li Y, Liu Z, Chen L, Qiao H, Wang L, and Zhu C: Protection by silibinin against experimental ischemic stroke: Up-regulated pAkt, pmTOR, HIF-1 $\alpha$ and Bcl-2, downregulated Bax, NF-кB expression in Neurosci Lett. (2012) 529:45-50.

[23] Nencini C, Giorgi G, and Micheli L: Protective effect of silymarin on oxidative stress in rat brain in phytomedicine. (2007) 14:129-135.

[24] Sathyasaikumar KV, Swapna I, Reddy PV, Murthy CRK, Roy KR, Gupta AD, Senthilkumaran B, and Reddanna P: Co-administration of C-phycocyanin ameliorates thioacetamide-induced hepatic encephalopathy in Wistar rats. J NeurolSci. (2007) 252(1):67-75. 
[25] Cengiz M, Ayhanci A, Kutlu HM, Musmul A: Potential therapeutic effects of silymarin and silymarin-loaded solid lipidnanoparticles on experimental kidney damage in BALB/c mice: biochemical and histopathological evaluation. Turk J Biol (2016) 40: 807-814

[26] Mansour, HH, Hafez, HF, Fahmy, NM., Silymarin Modulates Cisplatin-Induced Oxidative Stress and Hepatotoxicity in Rats. Journal of Biochemistry and Molecular Biology, Vol. 39, No. 6, November (2006), pp. 656-661

[27] Bashir S, Sharma Y, Irshad M, Nag TC, Tiwari M, Kabra M, and Dogra TD: Arsenic induced apoptosis in rat liver following repeated 60 days exposure in Toxicology. (2016)217 63-70.

[28] Chen LQ, Wei JS, Lei ZN, Zhang LM, Liu Y, and Sun AY: Induction of Bcl-2 and Bax Was Related to Hyperphosphorylation of Tau and Neuronal Death Induced by Okadaic Acid in Rat Brain inThe Anatomical Record Part A. (2005)287A:1236-1245.

[29] Yip KW and Reed JC: Bcl-2 family proteins and cancer in Oncogene (2008)27(50):6398-406.

[30] Mohan S, Abdelwahab SI, Kamalidehghan B, Syam S, May KS, Harmal SM, Shafifiyaz N, Hadi AHA, Hashim NM, Rahmani M, Taha MME, Cheah SC, and Zajmi A: Involvement of NF- $\kappa$ B and Bcl2/Bax signaling pathways in the apoptosis of MCF7 cells induced by a xanthone compound Pyrano cycloartobiloxanthone A. Phytomedicine. (2012)19(11):1007-15. [32] Hector S and Prehn JH: Apoptosis signaling proteins as prognostic biomarkers in colorectal cancer: a review in Biochim Biophys Acta. (2009)1795(2):117-29.

[31] El-Ghazaly MAE, Rashed EF, Shafey GM, Zaki HF, and Attia AS: Amelioration of thioacetamide-induced hepatic encephalopathy in rats by low-dose gamma irradiation in Environ. Sci. Pollut. Res. (2019) 27(1):334-343.

[32] Khanna A and Trigun SK: Resveratrol Normalizes Hyperammonemia Induced Pro-Inflammatory and ProApoptotic Conditions in Rat Brain inInt J Complement Alt Med. (2016)4(2):00115.

[33] Idriss H and Naismith JH: TNF Alpha and the TNF Receptor Superfamily: Structure-Function Relationship(s) Microsc Res Tech. (2000); 50(3):184-95.

[34] Yuan J and Yankner BA: Apoptosis in the nervous system in nature. (2000)407(6805):802-809.

[35] El-Marasy SA, El Awdan SA, and Abd-Elsalam RM: Protective role of chrysin on thioacetamide-induced hepatic encephalopathy in rats inChem. -Biol. Interact. (2018); 299:111-119.

[36] Kyrylkova K, Kyryachenko S, Leid M and Kioussi C. Detection of apoptosis by TUNEL assay in Methods Mol Biol. (2012)887:41-7.

[37] Bustamante J, Lores-Arnaiz S, Tallis S. Rosello DM, Lago N, Lemberg A, Boveris A, and Perazzo JC: Mitochondrial dysfunction as a mediator of hippocampal apoptosis in a model of hepatic encephalopathy in Mohl Cell Biochem. (2011) 354:231-240 